\title{
PRECIPITAÇÃO E EROSÃO DO SOLO NA SERRA DAS MATAS NO AMBIENTE DO SEMIÁRIDO CEARENSE
}

\author{
José Falcão Sobrinho ${ }^{1}$
}

\section{RESUMO:}

O presente ensaio é fruto da pesquisa realizada no município de Monsenhor Tabosa (CE), localizado em um maciço residual úmido e, este, conhecido por Serra das Matas. Decorrente de atividades agrícolas voltadas ao emprego da queima e da broca, os processos erosivos veem intensificando nesse ambiente, principalmente no período chuvoso, sendo as precipitações concentradas e torrenciais. Daí objetiva-se analisar a relação da precipitação com os processos erosivos, utilizandose do emprego de experimentos e análises laboratoriais.

PALAVRAS CHAVE: Semiárido, práticas agrícolas, desmatamento.

\section{RAINFALL AND SOIL EROSION IN SERRA DAS MATAS IN THE SEMI-ARID ENVIRONMENT CEARENSE}

\begin{abstract}
:
This essay is the result of research conducted in the city of Monsenhor Tabosa (CE) located in a damp residual mass, known as Serra das Matas. Arising from agricultural activities for the use of the drill and firing, erosive processes intensifying see this environment, especially in the rainy season, a concentrated and torrential rainfall. Hence, the objective is to analyze the relationship of precipitation erosion processes, using the use of experiments and laboratory analyzes.
\end{abstract}

KEYWORDS: Semi-arid, agricultural practices, deforestation

\section{LA PRECIPITACIÓN Y LA EROSIÓN DEL SUELO EN EL BOSQUE EN SIERRA SEMIÁRIDO CEARENSE MEDIO AMBIENTE}

RESUMEN:

Este ensayo es el resultado de la investigación llevada a cabo en el municipio de Monseñor Tabosa ((CE), que se encuentra en una masa residual húmeda y, esto, conocida como Serra das Matas. Debido a las actividades agrícolas relacionadas con el empleo y la quema de la broca, la erosión ver intensificando en este entorno, especialmente durante la temporada de lluvias, y la precipitación concentrada y torrencial. De ahí que el objetivo es analizar la relación entre los procesos de erosión de precipitación, mediante experimentos de empleo y pruebas de laboratório.

PALABRAS CLAVE: semiárido, las prácticas agrícolas, la deforestación.

\footnotetext{
${ }^{1}$ Professor Doutor do Mestrado Acadêmico em Geografia - Universidade Estadual Vale do Acaraú/UVA falcao.sobral@gmail.com
} 


\section{INTRODUÇÃO}

A erosão e a conservação do solo são desafios que acompanham o homem desde o início da agricultura. Com a evolução da mecanização e do cultivo em áreas extensivas a magnitude da destruição da natureza e da contaminação da água evoluiu proporcionalmente. A erosão do solo afeta a vida de diversas formas. As perdas de solo pela erosão afetam todo um povo, porém, principalmente o lavrador. O Brasil perde, por erosão laminar, cerca de quinhentos milhões de toneladas de terra anualmente; esse prejuízo lento e continuado que a erosão do solo tem ocasionado a nossa economia vem repercutindo, já de maneira nítida e insofismável, a fisionomia depauperada de algumas de nossas regiões.

O aumento da utilização agrícola das terras vem exercendo uma forte pressão nos solos, devido ao crescimento exponencial da população, como também do poder aquisitivo. De acordo com Silva et al. (1986), a limpeza da área é feita nos meses de dezembro e janeiro utilizando-se das práticas do desmatamento e das queimadas, ficando o solo totalmente exposto aos processos erosivos, justamente no início das chuvas. Na Serra das Matas, o problema de desmatamento nas vertentes torna-se um agravante ao processo erosivo decorrentes das precipitações, por se tratar de um ambiente com elevado índice de declividade, fato este associado ao suporte geológico, ou seja, uma estrutura do cristalino, que dificulta a infiltração da água, aumentando o escoamento superficial e, conseqüentemente, intensifica a erosão do solo, principalmente na estação chuvosa.

\section{CARACTERÍSTICAS DA ÁREA DE ESTUDO.}

A Serra das Matas é composta por elevações que chegam a $1.000 \mathrm{~m}$ de altitude, intercaladas com patamares que oscilam entre 500 a $700 \mathrm{~m}$, amparados por migmatitos, conforme mapa geológico do estado do Ceará, elaborado pelo CRPM (2003) e apresenta efeitos do tectonismo plástico e ruptural.

Merece destacar que as cristas ressaltam a altivez das formas da Serra e se estendem sobre a área do platô, ultrapassando o nível de $850 \mathrm{~m}$. O posicionamento da Serra das Matas tem um importante papel na rede de drenagem em todo 0 estado. Apresenta as nascentes do rio Quixeramobim, que compõe a maior bacia do 
estado do Ceará e deságua a leste do mesmo. E o outro grande rio, que compõem a segunda maior bacia hidrográfica, é o rio Acaraú.

Observam-se, neste ambiente, uma forma de relevo menos acidentado na porção central, com topos convexos e formas tabulares. É comum a presença de solos Podzólicos (Argissolos), com espessuras que chegam a mais de 1 metro. A vegetação, nessa área, corresponde a um porte elevado, arbóreo, ainda que resquício e pontual, existem algumas variações de espécies. Vale ressaltar que este tipo de solo é o encontrado em nossa área experimental.

São as áreas ocupadas primariamente por florestas e que justificariam a toponímia do compartimento em questão. Nos demais setores, as feições de cristas e vales profundos constituem as evidências principais.

Para leste da Serra, há uma grande freqüência de matacões, mesmo nas áreas mais elevadas, as formas aguçadas orientadas segundo a direção SE-NW. Prevalecem nesse ambiente os solos Litólicos (Neossolos Litólicos). As encostas desnudas e aparentemente as feições de declives são mais acentuadas. A vegetação é de porte arbustivo com larga incidência de plantas da caatinga, compartilhando com uma vegetação de palma forrageira.

Tais condições, em muito, são oriundas de um processo de ocupação da área, onde as vertentes foram desmatadas e substituídas por culturas secundárias, desde a agricultura de subsistência como o milho e o feijão até o emprego do algodão, da mamona e do café. Em um processo de desmatamento, são verificadas a erosão e denudação das vertentes.

\section{OBJETIVO}

Quantificar e avaliar o índice de precipitação e a sua capacidade de erosão em diversos tipos de manejo do solo em ambientes da Serra das Matas.

\section{METODOLOGIA}

O primeiro passo foi à escolha da área para montagem do experimento, obedecendo a compartimentação geomorfológica, no caso em um maciço residual úmido, denominado de Serra das Matas cuja localização é Latitude (S) 4 47' 22"' e 
Longitude (W) $40^{\circ} 03^{\prime} 48^{\prime \prime}$. Este contém as características mais representativas da serra. Sobre a estrutura geológica a área, situa-se no Complexo Tamboril-Santa Quitéria, prevalecendo uma associação de granito-migmatitica, conforme CPRM (1993).

Com base em Falcão Sobrinho e Falcão (2004), foram delimitas três áreas para objeto de estudo: a) uma área que tenha sido conservada há pelo menos 10 anos, sem intervenção antrópica; b) uma área em pousio há pelo menos três anos e c) uma área com uso contínuo, ou seja, que esteja sendo praticado um tipo de cultura ao longo de vários anos, no caso, plantio de milho que é a cultura mais empregada no semiárido cearense.

Foi feita uma limpeza do terreno para uniformizar a área experimental, com uso de uma enxada, com base nos seguintes procedimentos: Para quantificar as taxas erosivas montamos duas parcelas experimentais $(2 \mathrm{~m} \times 10 \mathrm{~m})$ em cada área, sendo as mesmas divididas no cumprimento, ao meio, por uma outra chapa alumínio, ficando cada parcela, uma em solo sem vegetação e outra em solo com vegetação, situadas em uma declividade de $12^{\circ}$, medidas com um clinômetro. Cada área mantinha a seguinte distância aproximada: de 100m entre uma ou outra. Foram utilizadas placas de alumínio com 2 a $4 \mathrm{~mm}$ de espessura com $50 \mathrm{~cm}$ de largura, sendo enterrado $10 \mathrm{~cm}$ e $40 \mathrm{~cm}$ acima do solo. Na parte inferior, foi conectada uma calha para receber o material erodido. Galões de plásticos foram interligados as calhas, para captar a água com sedimentos, quando ultrapassado o limite de coleta da calha.

O monitoramento foi realizado diariamente durante um período chuvoso, de janeiro a julho. Coletaram-se os sedimentos, em cada calha e nos galões coletores. Efetuaram-se a medição, a pesagem e a análise da composição granulométrica dos sedimentos e quantidade de matéria orgânica recolhida. A quantidade de material em cada parcela que continha vegetação não foi expressiva, com isso as análises dos dados reportaram as demais parcelas. $O$ índice de precipitação foi realizado com o auxílio de um pluviômetro. Conforme Bertoni e Lombardi Neto (1999), para a determinação das perdas por erosão, sob chuva natural, com talhos munidos de sistemas coletores, os resultados tornar-se-iam mais representativos, ainda, com as determinações por um tempo mais prolongado. No caso, o experimento foi realizado 
no período de dois anos, em 2004 e 2005, somente no período chuvoso, em que os pequenos agricultores utilizam a pratica da agricultura.

O solo erodido foi pesado e, enviadas amostras ao Centro de Estudos Tecnológicos (CENTEC) onde foi feito análise de física, determinando os valores de areia, silte e argila, bem como a densidade e porosidade. A análise química consistiu na identificação dos nutrientes: matéria orgânica, cálcio, potássio, magnésio, pH, sódio e saturação de bases. Adotamos para análise dos dados: a) erosividade da chuva; b) a erodibilidade, c) o fator topográfico e d) uso, manejo e conservação do solo. Consistiram na análise dos dados obtidos nas parcelas de solo: com plantio, em pousio e com vegetação. Foi analisada a relação percentual de cada área.

\section{RESULATDOS E DISCUSSÕES:}

Os resultados alcançados e as avaliações feitas permitiram testar alguns aspectos da Equação Universal de Perdas de Solos de Wishmeier e Smith, até hoje, o método mais conhecido e utilizado internacionalmente. Buscou-se levantar através de alguns parâmetros dessa Equação e a sua aplicação às condições da Região e com esse procedimento.

Nas áreas em que as parcelas continham vegetação não houve erosão. Apesar do caráter inicial em termos de pesquisa sobre erosão dos solos, em uma área de maciço no semiárido, foi-nos permitido obter os seguintes resultados preliminares da remoção por erosão, onde as chuvas representaram o principal elemento climático altamente relacionado com os desequilíbrios que se apresentaram. A variação espacial da intensidade das precipitações (volume), associada a sua freqüência (concentração em alguns meses do ano), foram fatores primordiais para avaliar o resultado do material erodido. (ver quadros 1 e 2)

Verifica-se o poder da água no carreamento do solo, este resultado é coerente com a prática realizada pelos agricultores locais, onde anualmente, quando começam a preparar as terras para o plantio inicia-se o processo de remoção de nutrientes pela erosão. (Quadro 1).

Podemos observar que a quantidade de material erodido acompanha o índice da precipitação. Fato este relacionado à precipitação total mensal, já que o índice diário é alternado. 
No quadro 1, nos meses de janeiro, fevereiro, março, abril e junho, em apenas 3 dias de chuva tem-se $50 \%$ do solo erodo.

É possível visualizar que o ano de 2005 apresentou algumas particularidades na parcela de mata. A mesma superou, no mês de maio, a área de pousio, levandose em conta o material erodido.

Outra particularidade refere-se à área de pousio, que no mês de fevereiro, teve um índice de erosão maior que á área de plantio.

Com relação às propriedades físicas, podemos verificar que os solos de todos os sistemas de manejo apresentaram a mesma classe textural franco arenoso em todo o perfil, com exceção do solo de mata que mostrou, a partir dos $15 \mathrm{~cm}$, uma maior quantidade de argila se enquadrando na classe de textura franco argiloarenoso. A seguir, tem-se a tabela 1, com as características do solo.

$\mathrm{Na}$ área de plantio com milho e feijão, a densidade do solo (Ds) atingiu um valor elevado $\left(1,50 \mathrm{~g} / \mathrm{cm}^{3}\right)$ na profundidade de $0-5 \mathrm{~cm}$ superior aos demais sistemas de manejo, o que caracteriza uma grave compactação e é indicativo, decerto, de degradação do solo. Além disso, esse sistema de manejo mostrou uma porosidade total (PT) em torno de $43,8 \%$ na mesma profundidade citada em relação aos demais sistemas de manejo que apresentaram valores próximos a $50 \%$.

É possível que o aumento de Ds e a redução da PT no sistema de plantio convencional estejam relacionados com o processo constante de umedecimento e secagem e, ao impacto de gotas de chuvas sobre a superfície do solo em função da ausência de cobertura vegetal nessa área, favorecendo, assim, a desagregação e remoção de partículas e contribuindo para a translocação de partículas mais finas para os horizontes inferiores causando obstrução dos poros. Este fato possibilita maior arraste de partículas no sentido da declividade nesse sistema, pelo efeito do escorrimento superficial de maior volume de água, o que, de certa forma, favorece os processos erosivos.

No tratamento de plantio convencional, verifica-se uma diminuição da fração argila de $40 \%$ da profundidade superficial para a camada de 5 a $10 \mathrm{~cm}$, o que se pode comprovar que houve um processo de erosão mais intenso nesse sistema de manejo, visto que a fração argila, por ser de menor tamanho e peso, é mais facilmente carreada pelas enxurradas. 
A partir da tabela 2, o que observamos é que as taxas de erosão do material erodido apresentam índices significativos nos teores de areia, silte e argila. Apresentam, pois, uma relação direta com o material coletado no momento da montagem do experimento. Esses dados evidenciam o empobrecimento e tendência ao declínio da capacidade de suporte e desenvolvimento vegetal, indo a refletir, diretamente nas condições de equilíbrio entre adições e perdas.

Quadro 1: Distribuição mensal da precipitação e solo erodido na Serra das Matas - Ano 2004.

\begin{tabular}{|c|c|c|c|c|c|c|c|c|c|c|c|c|c|c|}
\hline \multirow[t]{2}{*}{ M1 } & \multirow[t]{2}{*}{ P } & \multicolumn{3}{|c|}{ SEA } & \multirow[t]{2}{*}{ M2 } & \multirow[t]{2}{*}{$P$} & \multicolumn{3}{|c|}{ SEA } & \multirow[t]{2}{*}{ M3 } & \multirow[t]{2}{*}{ P } & \multicolumn{3}{|c|}{ SEA } \\
\hline & & PL & PO & V & & & $\mathbf{P L}$ & PO & V & & & PL & PO & $\mathbf{V}$ \\
\hline 1 & & & & & 1 & & & & & 1 & 19,0 & 1.230 & 980 & 780 \\
\hline 5 & & & & & 5 & & 4,1 & 98 & 45 & 5 & & & & \\
\hline 6 & & & & & 6 & & 9,4 & 760 & 250 & 6 & & & & \\
\hline 7 & & & & & 7 & & 1,0 & - & 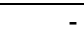 & 7 & & & & \\
\hline 8 & & & & & 8 & & 4,0 & 8 & 12 & 8 & & & & \\
\hline 9 & & & & & 9 & & & & & 9 & 6,1 & 120 & 310 & 300 \\
\hline 11 & & & & & 11 & & & & & 11 & 49,2 & 5.010 & 3.970 & 3.070 \\
\hline 12 & 10,3 & 130 & 85 & 30 & 12 & 22,5 & 760 & 510 & 450 & 12 & 25,0 & 1.800 & 1.020 & 440 \\
\hline 13 & & & & & 13 & 13,8 & 580 & 130 & 165 & 13 & & & & \\
\hline 14 & & & & & 14 & & & & & 14 & 1,5 & 10 & 15 & - \\
\hline 15 & 19,8 & 910 & 650 & 330 & 15 & 25,2 & 1010 & 780 & 350 & 15 & & & & \\
\hline 16 & & & & & 16 & 22,5 & 760 & 510 & 450 & 16 & & & & \\
\hline 18 & 31,5 & 3.110 & 3.200 & 980 & 18 & & & & & 18 & 1,8 & 20 & - & - \\
\hline 21 & 8,5 & 1.150 & 1.300 & 650 & 21 & & & & & 21 & & & & \\
\hline 22 & 80,5 & 9.210 & 6.030 & 5.440 & 22 & & & & & 22 & & & & \\
\hline 23 & 48,5 & 5.100 & 4.740 & 3.000 & 23 & & & & & 23 & & & & \\
\hline 24 & 24,0 & 890 & 1.100 & 930 & 24 & & & & & 24 & 2,5 & 35 & - & - \\
\hline 25 & 98,0 & 9.720 & 5.460 & 4.200 & 25 & & & & & 25 & & & & \\
\hline 26 & 38,4 & 680 & 940 & 650 & 26 & & & & & 26 & 24,4 & 1.100 & 1.300 & 760 \\
\hline 27 & 81,0 & 5.120 & 2.100 & 1.350 & 27 & & & & & 27 & & & & \\
\hline 28 & 37,4 & 1.050 & 659 & 780 & 28 & 12,8 & 290 & 190 & 60 & 28 & & & & \\
\hline 29 & 8,8 & 90 & 101 & 430 & 29 & & & & & 29 & & & & \\
\hline 30 & 107,0 & 9.120 & 7.100 & 7.460 & 30 & & & & & 30 & & & & \\
\hline 31 & 2,5 & & 98 & 330 & 31 & & & & & 31 & & & & \\
\hline$T$ & 596,2 & 46.260 & 33.563 & 26.560 & $T$ & 93,1 & 3506 & 1.917 & 1.130 & $T$ & 140,5 & 9.655 & 7.790 & 5.465 \\
\hline M4 & $\mathbf{P}$ & & SEA & & M5 & $\mathbf{P}$ & & SEA & & M6 & $\mathbf{P}$ & & SEA & \\
\hline 2 & & & & & 2 & & & & & 2 & 10,8 & 220 & 50 & 185 \\
\hline 4 & 6,5 & 4501 & 210 & 90 & 4 & & & & & 4 & 3,0 & 60 & 70 & 20 \\
\hline 5 & 5,8 & 125 & 120 & 150 & 5 & 8,8 & 740 & 330 & 460 & 5 & & & & \\
\hline 6 & 3,0 & 45 & 25 & 15 & 6 & & & & & 6 & 4,0 & 180 & 110 & 120 \\
\hline 9 & & & & & 9 & 2,8 & 70 & 35 & 60 & 9 & & & & \\
\hline 11 & & & & & 11 & & & & & 11 & 1,5 & - & 20 & - \\
\hline 12 & 2,1 & - & 5 & 50 & 12 & & & & & 12 & & & & \\
\hline 13 & 2,0 & 15 & 5 & 10 & 13 & & & & & 13 & & & & \\
\hline 14 & & & & & 14 & 3,2 & 110 & 95 & 95 & 14 & & & & \\
\hline 15 & & & & & 15 & & & & & 15 & $17 ., 8$ & 1.130 & 540 & 220 \\
\hline 16 & & & & & 16 & & & & & 16 & 1,5 & 20 & 15 & 15 \\
\hline 17 & & & & & 17 & & & & & 17 & 4,2 & 130 & 90 & 220 \\
\hline 18 & & & & & 18 & & & & & 18 & 10,9 & 610 & 330 & 310 \\
\hline 19 & 6,0 & 810 & 320 & 550 & 19 & & & & & 19 & 14,8 & 850 & 380 & 90 \\
\hline 20 & & & & & 20 & & & & & 20 & 1,6 & - & - & - \\
\hline 21 & & & & & 21 & 45,5 & 5.880 & 6790 & 4.020 & 21 & 6,3 & 175 & 410 & 320 \\
\hline 22 & 22,5 & 890 & 850 & 1.150 & 22 & & & & & 22 & 23,2 & 2.080 & 750 & 600 \\
\hline 23 & 6,9 & 210 & 300 & 270 & 23 & & & & & 23 & & & & \\
\hline 26 & & & & & 26 & 1,6 & - & - & - & 26 & & & & \\
\hline 27 & 26,3 & 5.160 & 3.580 & 1.270 & 27 & & & & & 27 & 37,1 & 6.700 & 6.970 & 3.450 \\
\hline 28 & & & & & 28 & & & & & 28 & 2,7 & 110 & 95 & 40 \\
\hline 29 & & & & & 29 & 1,9 & 70 & 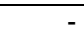 & 10 & 29 & & & & \\
\hline 31 & & & & & 31 & 3,2 & 750 & 190 & 550 & 31 & & & & \\
\hline$T$ & 81,1 & 11.756 & 5.415 & 3.555 & $T$ & 67 & 7.620 & 7.440 & 5.195 & $T$ & 139,4 & 12.265 & 9.830 & 5.590 \\
\hline
\end{tabular}


LEGENDA: M1 - janeiro M2 - fevereiro M3 - março M4-abril M5 - maio

M6 - junho $P$ - precipitação $(\mathrm{mm})$

SEA - solo eerodido em área $(\mathrm{g})$

PL - plantio (g) Po - pousio (g) V - vegetação (g)

Quadro 2: Distribuição mensal da precipitação e solo erodido na Serra das Matas (CE) - Ano 2005

\begin{tabular}{|c|c|c|c|c|c|c|c|c|c|c|c|c|c|c|}
\hline \multirow[t]{2}{*}{ M1 } & \multirow[t]{2}{*}{$\mathbf{P}$} & \multicolumn{3}{|c|}{ SEA } & \multirow[t]{2}{*}{ M2 } & \multirow[t]{2}{*}{$\mathbf{P}$} & \multicolumn{3}{|c|}{ SEA } & \multirow[t]{2}{*}{ M3 } & \multirow[t]{2}{*}{$\mathbf{P}$} & \multicolumn{3}{|c|}{ SEA } \\
\hline & & PL & PO & $\mathbf{V}$ & & & PL & PO & $\mathbf{V}$ & & & $\mathbf{P L}$ & PO & V \\
\hline 11 & & & & & 11 & & & & & 11 & 8,2 & 320 & 120 & 215 \\
\hline 14 & 3,4 & 132 & 150 & 90 & 14 & & & & & 14 & & & & \\
\hline 15 & 70,1 & 8.700 & 6.630 & 3.500 & 15 & 3,2 & 80 & 40 & 65 & 15 & & & & \\
\hline 16 & & & & & 16 & 3,6 & 120 & 95 & 100 & 16 & & & & \\
\hline 17 & 12,5 & 2.400 & 2.100 & 1.700 & 17 & 20,9 & 2.360 & 2.450 & 980 & 17 & 4,2 & 180 & 110 & 50 \\
\hline 18 & & & & & 18 & 17,2 & 1.200 & 1.180 & 720 & 18 & & & & \\
\hline 19 & & & & & 19 & 1,0 & - & - & - & 19 & 17,7 & 2.300 & 980 & 750 \\
\hline 20 & 3,8 & 70 & 35 & 80 & 20 & & & & & 20 & 6,6 & 130 & 100 & 105 \\
\hline 21 & & & & & 21 & & & & & 21 & 5,3 & 320 & 140 & 60 \\
\hline 22 & & & & & 22 & & & & & 22 & 3,1 & 40 & - & 15 \\
\hline 24 & 2,8 & 55 & 70 & 45 & 24 & & & & & 24 & & & & \\
\hline 25 & 6,0 & 420 & 180 & 75 & 25 & & & & & 25 & 19,0 & 2.150 & 1.010 & 1.125 \\
\hline 26 & 41,0 & 4.320 & 3.280 & 2.250 & 26 & & & & & 26 & 41,0 & 4.300 & 3.090 & 2.960 \\
\hline 27 & 5,5 & 750 & 550 & 600 & 27 & & & & & 27 & 4,4 & 90 & 130 & 50 \\
\hline 28 & & & & & 28 & & & & & 28 & 28,2 & 3.600 & 3.130 & 1.380 \\
\hline 29 & 3,2 & 350 & 400 & 510 & 29 & & & & & 29 & 3,6 & 20 & 190 & 54 \\
\hline 30 & & & & & 30 & & & & & 30 & 13,0 & 320 & 710 & 125 \\
\hline 31 & & & & & 31 & & & & & 31 & 1,8 & 10 & 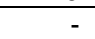 & 25 \\
\hline $\mathrm{T}$ & 148,3 & $\begin{array}{l}17.197 \\
\end{array}$ & 13.395 & 8.850 & $T$ & 45,9 & 3.760 & 3.765 & 1.865 & $T$ & 156,1 & 13.780 & 9.710 & 6.914 \\
\hline \multirow[t]{2}{*}{ M4 } & \multirow[t]{2}{*}{$\mathbf{P}$} & \multicolumn{3}{|c|}{ SEA } & \multirow[t]{2}{*}{ M5 } & \multirow[t]{2}{*}{$\mathbf{P}$} & \multicolumn{3}{|c|}{ SEA } & M6 & $\mathbf{P}$ & \multicolumn{3}{|c|}{ SEA } \\
\hline & & PL & PO & V & & & PL & PO & V & & & PL & PO & V \\
\hline 1 & 3,6 & 420 & 355 & 80 & 1 & & & & & 1 & 3,6 & 220 & 230 & 240 \\
\hline 2 & 1,6 & 75 & 10 & $\begin{array}{ll}- \\
-\end{array}$ & 2 & & & & & 2 & 10,1 & 950 & 910 & 410 \\
\hline 3 & & & & & 3 & 19,1 & 1.230 & 720 & 880 & 3 & 11,0 & 810 & 230 & 450 \\
\hline 4 & 2,2 & 78 & 80 & 10 & 4 & & & & & 4 & & & & \\
\hline 5 & & & & & 5 & & & & & 5 & 4,0 & 110 & 210 & 250 \\
\hline 6 & & & & & 6 & & & & & 6 & 5,5 & 80 & 130 & 220 \\
\hline 7 & & & & & 7 & & & & & 7 & 2,0 & - & 30 & 15 \\
\hline 8 & 20,0 & 1720 & 1.110 & 1.505 & 8 & & & & & 8 & 3,5 & 200 & 320 & 185 \\
\hline 9 & 1,0 & - & 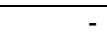 & 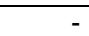 & 9 & 3,6 & 150 & 130 & 120 & 9 & 3,4 & 230 & 210 & 130 \\
\hline 10 & 2,7 & 55 & 75 & 15 & 10 & & & & & 10 & & & & \\
\hline 12 & & & & & 12 & 4,5 & 125 & 185 & 310 & 12 & 2,0 & 5 & 10 & - \\
\hline 14 & & & & & 13 & & & & & 13 & & & & \\
\hline 15 & 3,5 & 180 & 220 & 20 & 14 & 10,1 & 1.050 & 760 & 2.080 & 14 & 5,1 & 230 & 120 & 80 \\
\hline 16 & 3,6 & 430 & 530 & 10 & 15 & 5,3 & 220 & 320 & 230 & 15 & & & & \\
\hline 17 & & & & & 16 & 2,4 & 70 & 110 & 80 & 16 & 5,5 & 890 & 330 & 520 \\
\hline 18 & & & & & 17 & 3,1 & 135 & 90 & 20 & 17 & & & & \\
\hline 19 & & & & & 18 & 34,5 & 3.630 & 2.700 & 330 & 18 & 2,0 & 75 & - & 110 \\
\hline 20 & & & & & 19 & 1,1 & - & - & - & 19 & & & & \\
\hline 21 & 6,2 & 455 & 200 & 310 & 20 & & & & & 20 & & & & \\
\hline 24 & 3,2 & 80 & 20 & 70 & 21 & 7,5 & 75 & 95 & 210 & 21 & & & & \\
\hline 26 & & & & & 24 & 11,3 & 560 & 580 & 420 & 24 & & & & \\
\hline 27 & 14,3 & 980 & 330 & 640 & 26 & 1,6 & - & - & - & 26 & & & & \\
\hline 28 & 2,2 & - & - & 15 & 27 & & & & & 27 & & & & \\
\hline 29 & & & & & 28 & 7,2 & 350 & 125 & 510 & 28 & & & & \\
\hline 30 & 22,2 & 2.130 & 2.150 & 1.750 & 29 & 5,5 & 800 & 550 & 950 & 29 & & & & \\
\hline 31 & & & & & 30 & 3,2 & 310 & 180 & 650 & 30 & & & & \\
\hline$T$ & 86,7 & 6.441 & 5.080 & 4.425 & $T$ & 120 & 8.705 & 6.545 & 6.790 & $T$ & 57,7 & 3.800 & 2.730 & 2.610 \\
\hline
\end{tabular}

LEGENDA: M1 - janeiro M2 - fevereiro M3 - março M4-abril M5 - maio

M6 - junho $P$ - precipitação $(\mathrm{mm})$

SEA - solo eerodido em área $(g)$

PL - plantio (g) Po - pousio (g) V - vegetação (g) 
Tabela 1: Características físicas de um Argissolo sob diferentes tipos de manejo. Serra das Matas

\begin{tabular}{|c|c|c|c|c|c|c|c|}
\hline Profundidade & $\begin{array}{c}\text { Areia } \\
\text { grossa }\end{array}$ & Areia fina & Silte & Argila & $\begin{array}{c}\text { Classificação } \\
\text { textural }\end{array}$ & Ds & PT \\
\hline \multicolumn{6}{|c|}{ 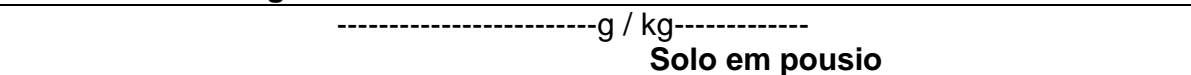 } & $\mathrm{g} \mathrm{cm}^{-3}$ & $\%$ \\
\hline $0-5 \mathrm{~cm}$ & 37,2 & 25,5 & 23,3 & 14,0 & Franco arenoso & 1,33 & 43,6 \\
\hline $5-10 \mathrm{~cm}$ & 37,6 & 21,2 & 24,3 & 16,9 & Franco arenoso & 1,31 & 49,2 \\
\hline $10-15 \mathrm{~cm}$ & 34,4 & 21,7 & 26,9 & 17,0 & Franco arenoso & 1,28 & 48,1 \\
\hline $15-20 \mathrm{~cm}$ & 36,4 & 20,5 & 28,9 & 16,2 & Franco arenoso & 1,24 & 51,6 \\
\hline $20-25 \mathrm{~cm}$ & 35,9 & 21,5 & 26,4 & 16,2 & Franco arenoso & 1,19 & 54,1 \\
\hline $25-30 \mathrm{~cm}$ & 34,7 & 19,6 & 29,4 & 16,3 & Franco arenoso & 1,20 & 55,1 \\
\hline \multicolumn{8}{|c|}{ Solo com milho e feijão } \\
\hline $0-5 \mathrm{~cm}$ & 41,4 & 28,6 & 21,6 & 8,4 & Franco arenoso & 1,50 & 39,8 \\
\hline $5-10 \mathrm{~cm}$ & 40,5 & 24,3 & 23,2 & 12,0 & Franco arenoso & 1,42 & 45,7 \\
\hline $10-15 \mathrm{~cm}$ & 33,7 & 29,0 & 22,1 & 15,2 & Franco arenoso & 1,35 & 43,3 \\
\hline $15-20 \mathrm{~cm}$ & 33,3 & 27,6 & 25,1 & 14,0 & Franco arenoso & 1,32 & 43,2 \\
\hline $20-25 \mathrm{~cm}$ & 37,5 & 24,1 & 26,0 & 14,4 & Franco arenoso & 1,29 & 46,3 \\
\hline $25-30 \mathrm{~cm}$ & 33,6 & 23,9 & 26,8 & 15,7 & Franco arenoso & 1,29 & 45,2 \\
\hline \multicolumn{8}{|c|}{ Solo sob mata } \\
\hline $0-5 \mathrm{~cm}$ & 38,2 & 26,7 & 22,7 & 12,4 & Franco arenoso & 1,21 & 53,5 \\
\hline $5-10 \mathrm{~cm}$ & 37,7 & 24,6 & 22,8 & 14,9 & Franco arenoso & 1,19 & 50,1 \\
\hline $10-15 \mathrm{~cm}$ & 36,1 & 22,7 & 21,9 & 19,3 & Franco arenoso & 1,23 & 51,4 \\
\hline $15-20 \mathrm{~cm}$ & 28,0 & 26,0 & 24,1 & 21,9 & $\begin{array}{l}\text { Franco argilo- } \\
\text { arenoso }\end{array}$ & 1,25 & 52,3 \\
\hline $20-25 \mathrm{~cm}$ & 28,9 & 21,9 & 26,3 & 22,9 & $\begin{array}{l}\text { Franco argilo- } \\
\text { arenoso }\end{array}$ & 1,23 & 53,6 \\
\hline $25-30 \mathrm{~cm}$ & 31,8 & 21,1 & 24,2 & 22,9 & $\begin{array}{l}\text { Franco argilo- } \\
\text { arenoso }\end{array}$ & 1,21 & 51,0 \\
\hline
\end{tabular}

Tabela 2: Características físicas do solo erodido sob diferente tipo de manejo. Serra das Matas.

\begin{tabular}{|c|c|c|c|c|c|c|c|}
\hline Profundidade & $\begin{array}{l}\text { Areia } \\
\text { grossa }\end{array}$ & Areia fina & Silte & Argila & $\begin{array}{c}\text { Classificação } \\
\text { textural }\end{array}$ & Ds & PT \\
\hline & & 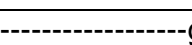 & g-- & & & $\mathrm{g} \mathrm{cm}^{-3}$ & $\%$ \\
\hline \multicolumn{8}{|c|}{ Solo em pousio } \\
\hline 2004 & 40,6 & 16,2 & 29,0 & 15,0 & franco arenoso & 1,32 & 2,62 \\
\hline 2005 & 40,3 & 25,3 & 24,7 & 9,7 & franco arenoso & 1,21 & 2,61 \\
\hline \multicolumn{8}{|c|}{ Solo com milho e feijão } \\
\hline 2004 & 49,0 & 23,0 & 21,6 & 6,4 & franco arenoso & 1,44 & 2,67 \\
\hline 2005 & 48,1 & 31,4 & 14,6 & 5,9 & franco arenoso & 1,38 & 2,64 \\
\hline \multicolumn{8}{|c|}{ Solo sob mata } \\
\hline 2004 & 49,0 & 23,0 & 21,6 & 6,4 & franco arenoso & 1,44 & 2,67 \\
\hline 2005 & 48,1 & 31,4 & 14,6 & 5,9 & franco arenoso & 1,38 & 2,64 \\
\hline
\end{tabular}

Os dados revelam que, em todas as situações referentes às práticas de manejo, a precipitação não exerce uma uniformidade em termos de quantidade de 
chuva e de material erodido. Isso pode estar relacionado à intensidade da chuva, está por sua vez pode relacionar-se à duas situação: (a) em ter a precipitação avolumada em um curto período de tempo e com isso desenvolver uma maior intensidade e (b) a distribuição resultar durante o dia, em menor velocidade e menor força.

Outra situação que difere na relação precipitação e a erosão, relaciona-se à deposição do solo, pois o mesmo pode percorrer entre no interior da calha durante uma certa distância e depositar-se ali, dependendo da intensidade da chuva. E, durante uma próxima chuva, mesmo com menor intensidade, esta condição ser o suficiente para o material erodido chegar à calha receptora.

Entretanto, outras situações são observadas, mediante os dados coletados:

\section{- Erodibilidade do solo}

Com base nos dados, chega-se ao fator erodibilidade do solo, que é a sua vulnerabilidade ou suscetibilidade à erosão. Uma recíproca da resistência à erosão. Um solo com alta suscetibilidade sofrerá mais erosão que um com baixa erodibilidade se ambos estiverem expostos a uma mesma chuva (BERTONI; LOMBARDI NETO, 1999).

Como sabemos a determinação do índice de erodibilidade é dada como sendo a razão entre a relação de dispersão (teor de argila natural/teor de argila dispersa) e a relação argila dispersa/unidade equivalente.

O relatório do RADAMBRASIL (1981) relata que a erodibilidade do solo é proporcional à seguinte relação:

$$
\frac{\% \text { areia }+\% \text { limo }}{\% \text { argila }}
$$

Levando-se em consideração os experimentos realizado verificou-se as seguintes perdas de solos na Serra das Matas: 
Quadro 3: Índice de dispersão do solo na Serra das Matas

\begin{tabular}{|c|c|}
\hline Amostra & Relação de dispersão \\
\hline $0-5 \mathrm{~cm}$ & 4,52 \\
\hline $5-10 \mathrm{~cm}$ & 3,91 \\
\hline $10-15 \mathrm{~cm}$ & 2,56 \\
\hline $15-20 \mathrm{~cm}$ & 4,35 \\
\hline $20-25 \mathrm{~cm}$ & 4,69 \\
\hline $25-30 \mathrm{~cm}$ & 4,20 \\
\hline
\end{tabular}

Como discutiremos a seguir, trata-se de valores elevados de potencial erosivo dos solos, cujos índices são crescentes em profundidade.

Bertoni e Lombardi Neto (1999) apontam que em solos mais próximos aos da Serra das Matas, os Podzolizados com cascalhos, apresentaram índices de erodibilidade maiores para o Estado de São Paulo, variando de 0,055 a 0,027.

\section{- Fator topográfico}

Quanto ao fator topográfica, nos foi permitido fazer algumas considerações, pautados em Bertoni (1959), que considera o comprimento de declive da encosta e a sua declividade ( $\mathrm{L}$ e S) normalmente analisados em conjunto (Fator Topográfico), através da seguinte fórmula.

$$
0,63 \quad 1,18
$$

$\mathrm{LS}=0,00984 . \mathrm{L} . \times \mathrm{S}$

Onde:

L é o comprimento da encosta, ou comprimento de rampa, em metros,

$S$ é a declividade expressa em porcentagem

Aplicando este fórmula ao município de a Serra das Matas, temos:

Quadro 4: Dados de declividade (S) e comprimento da vertente $(L)$ na Serra das Matas.

\begin{tabular}{|l|c|c|c|}
\hline \multicolumn{1}{|c|}{ Identificação } & Estação (1) & Estação (2) & Estação (3) \\
\hline Declividade (\%) & 30,6 & 32,5 & 30,6 \\
\hline Comprimento da vertente (m) & 67,0 & 65,0 & 65,0 \\
\hline Uso & Plantio & Mata fechada & Pousio \\
\hline
\end{tabular}

Quadro 5: Valores do Fator Topográfico (LxS) na Serra das Matas

\begin{tabular}{|c|c|c|c|}
\hline (LxS) & Estação (1) & Estação (2) & Estação (3) \\
\hline Fator Topográfico & 7,82 & 8,18 & 7,64 \\
\hline
\end{tabular}


A estação (2) apresentou o maior valor $(8,18)$, seguido da estação (1) cujo valor foi intermediário $(7,82)$ e da estação (3) que apresentou o menor valor $(7,64)$. A primeira vista o que ressalta é a proximidade dos valores, sendo pequenas as diferenças. Esses resultados refletem condições de $L$ (comprimento da vertente) e $S$ (declividade) também próximas. É muito provável que o maior valor para a Estação (2) deva-se às maiores declividades da mesma.

\section{- Uso, manejo e conservação dos solos}

Nesse item, vamos avaliar o fator Uso, Manejo e Conservação dos Solos dos experimentos dos três municípios considerados, sabendo de antemão que esse parâmetro da Equação Universal de Perdas de Solos, fator $\mathrm{CP}$, foi o único obtido experimentalmente, contribuindo, portanto para o enriquecimento das Pesquisas em Erosão do semiárido nordestino. $\mathrm{Na}$ Serra das Matas, o solo erodido apresentou as características apresentadas na tabela a seguir: 


\section{Periádica Eletrânica

Tabela 3: Solo erodido sob diferente tipo de manejo, na Serra das Matas

\begin{tabular}{|c|c|c|c|c|}
\hline & \multirow{3}{*}{$\begin{array}{c}\text { Precipitação } \\
(\mathrm{mm})\end{array}$} & \multicolumn{3}{|c|}{ Solo erodido } \\
\hline & & Plantio & Pousio & Vegetação \\
\hline \multirow{2}{*}{ Meses } & & \multicolumn{3}{|c|}{ (g) } \\
\hline & \multicolumn{4}{|c|}{2004} \\
\hline Janeiro & 596,2 & 46.260 & 33.563 & 26.560 \\
\hline Fevereiro & 93,1 & 3,506 & 1.917 & 1.130 \\
\hline Março & 140,5 & 9.655 & 7.790 & 5.465 \\
\hline Abril & 81,1 & 11.756 & 5.415 & 3.555 \\
\hline Maio & 67 & 7.620 & 7.440 & 5.195 \\
\hline Junho & 139,4 & 12.265 & 9.830 & 5.590 \\
\hline TOTAL & 1.117 .3 & 91.062 & 65.955 & 47.495 \\
\hline & \multicolumn{4}{|c|}{2005} \\
\hline Janeiro & 148,3 & 17.197 & 13.395 & 8.850 \\
\hline Fevereiro & 45,9 & 3.760 & 3.765 & 1.865 \\
\hline Março & 156,1 & 13.780 & 9.710 & 6.914 \\
\hline Abril & 86,7 & 6.441 & 5.080 & 4.425 \\
\hline Maio & 120 & 8.705 & 6.545 & 6.790 \\
\hline Junho & 57,7 & 3.800 & 2.730 & 2.610 \\
\hline TOTAL & 583,0 & 53.683 & 41.225 & 31.454 \\
\hline
\end{tabular}

Em 2004, com um total de $1117,3 \mathrm{~mm}$ de chuvas, o manejo relacionado ao plantio perdeu $43 \%$, ao pousio, $36 \%$, e a mata fechada, $22 \%$ sendo as perdas de terras proporcionais às chuvas e aos tipos de manejos.

Em 2005, chovendo cerca de terça parte do ano anterior, as perdas anuais foram $44 \%$ para o plantio, $35 \%$ para o pousio e $22 \%$ para a vegetação natural.

Pelo quadro acima, o sistema de manejo plantio convencional apresentou as maiores perdas, seguido do pousio e da mata fechada, sendo significativas as diferenças entre o plantio convencional e o da mata fechada em que as perdas desse último representam metade das perdas do primeiro sistema. Expressam, ainda, o predomínio da erosão laminar e envolve, seguramente, outras formas como a erosão linear, pois é notória a contribuição da enxurrada mostrada pela presença significativa da fração areia nas amostras de solos removidos pela erosão.

\section{- Análise Química do Solo na Serra das Matas}

Os resultados das análises químicas encontram-se na tabela 1, apresentaram os solos ao longo do perfil, com boas características químicas e saturação de bases superiores a $60 \%$, o que lhes confere um caráter eutrófico, $\mathrm{pH}$ próximo à neutralidade e teores elevados de matéria orgânica, conforme Alvarez V. et al. (1999). Com relação ao fósforo $(P)$, o solo com plantio de milho e feijão mostrou valor muito alto apenas na camada de 0 a $5 \mathrm{~cm}$, provavelmente, pelos altos teores de matéria orgânica na camada superficial, enquanto que nas demais camadas o teor deste nutriente pode ter sido exaurido em função do requerimento pelas culturas de milho e 
de feijão. Nos outros sistemas de manejos estudados, os valores de $\mathrm{P}$ foram médios e altos, em todo o perfil (tabela 4).

Tabela 4: Características químicas de um Argissolo sob diferente tipo de manejo, na Serra das Matas

\begin{tabular}{|c|c|c|c|c|c|c|c|c|c|}
\hline Profundidade & $\mathrm{pH}$ & MO & $\mathbf{P}$ & K & $\mathrm{Ca}$ & $\mathbf{M g}$ & $\mathrm{H}+\mathbf{A l}$ & SB & V \\
\hline \multirow{2}{*}{\multicolumn{10}{|c|}{$\begin{array}{l}\text { - } \\
\text { Solo em pousio }\end{array}$}} \\
\hline & & & & & & & & & \\
\hline $0-5 \mathrm{~cm}$ & 6,9 & 16,3 & 98 & 3,36 & 64,1 & 6,1 & 24,7 & 74,1 & 75 \\
\hline $5-10 \mathrm{~cm}$ & 6,3 & 12,54 & 81 & 2,94 & 55,0 & 15,0 & 31,2 & 72,9 & 70 \\
\hline $10-15 \mathrm{~cm}$ & 6,3 & 12,19 & 67 & 2,74 & 65,0 & 24,0 & 33,1 & 81,1 & 71 \\
\hline $15-20 \mathrm{~cm}$ & 6,5 & 10,0 & 32 & 2,70 & 58,0 & 1,0 & 29,7 & 61,2 & 69 \\
\hline $20-25 \mathrm{~cm}$ & 6,5 & 9,32 & 29 & 3,10 & 69,0 & 2,0 & 27,0 & 73,0 & 73 \\
\hline $25-30 \mathrm{~cm}$ & 6,4 & 8,79 & 21 & 3,20 & 88,0 & 1,5 & 20,1 & 92,0 & 82 \\
\hline \multicolumn{10}{|c|}{ Solo com milho e feijão } \\
\hline $0-5 \mathrm{~cm}$ & 6,8 & 9,9 & 24 & 4,0 & 56,0 & 15,9 & 29,5 & 75,9 & 72 \\
\hline $5-10 \mathrm{~cm}$ & 6,1 & 8,7 & 11 & 3,1 & 66,00 & 80,0 & 29,5 & 80,0 & 73 \\
\hline $10-15 \mathrm{~cm}$ & 6,1 & 7,9 & 7 & 2,7 & 57,0 & 78,6 & 26,2 & 78,6 & 75 \\
\hline $15-20 \mathrm{~cm}$ & 6,2 & 7,8 & 5 & 1,9 & 63,4 & 80,2 & 22,6 & 80,2 & 78 \\
\hline $20-25 \mathrm{~cm}$ & 6,5 & 5,3 & 5 & 1,52 & 64,0 & 13,5 & 17,3 & 79,0 & 82 \\
\hline $25-30 \mathrm{~cm}$ & 6,5 & 5,4 & 6 & 1,25 & 60,0 & 21,0 & 19,5 & 82,2 & 81 \\
\hline \multicolumn{10}{|c|}{ Solo sob mata } \\
\hline $0-5 \mathrm{~cm}$ & 6,9 & 20,2 & 121 & 7,11 & 64,4 & 11,0 & 14,5 & 82,5 & 85 \\
\hline $5-10 \mathrm{~cm}$ & 6,6 & 21,3 & 111 & 5,3 & 55,1 & 19,0 & 19,8 & 79,4 & 80 \\
\hline $10-15 \mathrm{~cm}$ & 6,8 & 15,2 & 81 & 4,2 & 65,8 & 8,1 & 20,7 & 78,1 & 79 \\
\hline $15-20 \mathrm{~cm}$ & 6,0 & 14,0 & 42 & 3,7 & 61,8 & 14,9 & 24,1 & 76,4 & 76 \\
\hline $20-25 \mathrm{~cm}$ & 6,5 & 12,8 & 28 & 2,4 & 67,6 & 6,7 & 25,5 & 76,7 & 75 \\
\hline $25-30 \mathrm{~cm}$ & 6,3 & 9,5 & 27 & 1,4 & 60,0 & 12,0 & 21,9 & 73,4 & 74 \\
\hline
\end{tabular}

Podemos verificar que, na análise do solo erodido o tratamento com plantio convencional mostrou uma melhor fertilidade principalmente com relação ao tratamento com mata (tabela 5), provavelmente pelo fato de uma maior perda de argila, pois essa partícula de solo possui a propriedade de reter cátions tais como cálcio, magnésio e potássio, elementos essenciais para o desenvolvimento das plantas.

A matéria orgânica foi perdida em grandes quantidades em todos os tratamentos (tabela 4) sendo proporcional ao conteúdo. Disponível originalmente presente ao solo e, ainda, porque a matéria orgânica é o primeiro constituinte a ser removido pela erosão, tendo em vista sua baixa densidade, concordando com os 
trabalhos de Seganfredo et al. (1997) e Schinck et al. (2000). Essa variável avaliada atingiu perda máxima de 20 e $27 \mathrm{~g}$ no sistema de plantio, sem cobertura vegetal, refletindo as maiores quantidades de solos erdodidos nesse tratamento (tabela 4).

McGregor et al. (1996), salientam que a perda de matéria orgânica por erosão tem grande importância para os processos de eutrofização de mananciais, na medida em que a biodegradação de componentes orgânicos em rios e lagos eleva as demandas bioquímicas de oxigênio, colocando em perigo a vida aquática.

Tabela 5: Características químicas dos sedimentos erodidos de um Argissolo, na Serra das Matas

\begin{tabular}{cccccccccc}
\hline Manejo & pH & Co & MO & P & K & Ca & Mg & Sb & V \\
\hline \multicolumn{7}{c}{} & \multicolumn{7}{c}{$\mathbf{2 0 0 4}$} \\
\hline Pousio & 7,0 & 10,02 & 17,27 & 21 & 4,0 & 58,0 & 24,0 & 88,1 & 79 \\
Plantio & 7,3 & 11,70 & 20,17 & 76 & 4,54 & 50,0 & 21,0 & 83,1 & 86 \\
Mata & 7,1 & 9,12 & 15,72 & 56 & 3,20 & 42,0 & 17,0 & 67,8 & 72 \\
& \multicolumn{7}{c}{$\mathbf{2 0 0 5}$} \\
Pousio & 7,6 & 15,90 & 27,41 & 73 & 5,74 & 94,0 & 37,0 & 144,0 & 91 \\
Plantio & 6,3 & 10,38 & 17,90 & 84 & 2,43 & 39,0 & 19,0 & 68,8 & 74 \\
Mata & 7,0 & 6,48 & 11,17 & 64 & 3,35 & 45,0 & 15,0 & 69,7 & 71 \\
\hline
\end{tabular}

O teor dos nutrientes estudados no sedimento da erosão foi, em geral, elevados nos três sistemas de manejo com características químicas parecidas com solos nas condições originais antes de ser erodido. O magnésio mostrou uma taxa de enriquecimento maior no sedimento erodido do que no solo de onde se originou, sendo, por isso, o nutriente mais problemático, juntamente com o carbono orgânico, em termos de contaminação ambiental, pelo efeito de eutrofização da água. Esse comportamento pode ser devido à textura do material transportado pela erosão, o qual, provavelmente, é rico em silte e argila do que o solo onde ele se originou, uma vez que essas frações granulométricas são as mais facilmente transportadas e mais rica em nutrientes adsorvidos (CHINCK, et al., 2000).

Os resultados apresentados nas tabelas 1, 2, 3 e 4, indicam eficiente controle da erosão do solo em pousio e de mata visto que houve uma redução de perda de solo na ordem de $20 \%$ e $50 \%$ e, respectivamente no ano de 2004 e de $35 \%$ a $40 \%$, no ano de 2005, em relação ao solo com plantio de milho e feijão. Essa diferença pode ser atribuída ao teor de matéria orgânica bem superior naqueles sistemas visto que esta tem a capacidade de absorver uma maior quantidade de água e, 


\section{Periádica Eletranica

consequentemente, diminuir o escoamento superficial e a perda de solo por erosão concordando com os resultados encontrados por Albuquerque et al., (2001).

\section{CONSIDERAÇÕES FINAIS}

Consideramos que os fatores experimentais, bem delimitados, mas sob uma análise bastante limitada, em termos de dimensão, deixa-nos a questionar sobre os dados, caso fossemos representá-los em um modelo para de fins de planejamento em todo o maciço. Fica proposto, que para fins de análises, em termo de processos, há de considerar a importância que deve ter as áreas agriculturáveis em nível de repouso, ou pousio. Os dados obtidos mostraram que o fator erosão em função da precipitação, mostrou-se menos intenso nas áreas com cobertura e com maior tempo de vegetação presente, o que influiu diretamente na estrutura do solo e em seus nutrientes presentes, conforme análises físicas e químicas. Associado a isso, e condicionando o todo, o fator relevo, que, através de suas declividades, evidenciou a natureza e magnitude dos processos, acelerando o deslocar dos nutrientes em seus elementos físicos e químicos de forma que estariam condicionadas as suas declividades. Sempre maior quanto mais acentuada for a vertente e, consequentemente, a intensidade da precipitação.

Pode-se concluir que o índice de precipitação é um fator primordial para análise, já que os gráficos apontaram a proporção do total de chuva proporcionalmente equivalente ao material erodido.

Apoio: FUNCAP - referente à $3^{\underline{a}}$ etapa de pesquisa da tese de doutorado realizada na FFLCH/USP, no curso de Geografia Física.

\section{REFERÊNCIAS BIBLIOGRÁFICAS}

ALBUQUERQUE, A. W; LOMBARDI NETO, F.; SRINIVASAN, V.S. Efeito do desmatamento da caatinga sobre as perdas de solo e água de um Luvissolo em Sumé (PB). R. Bras. Ci. Solo, 25: 121-128, 2001.

BERTONI, J; LOMBARDIO NETO. Conservação do Solo. São Paulo. Ícone Editora. 1999. CPRM. (2003). Mapa Geológico do Estado do Ceará. Escala: 1:500.000. Fortaleza, Ceará FALCÃO SOBRINHO, J.; FALCÃO, C.L.C. (2004). Técnicas de monitoramento de processos erosivos. (mimeografado). Sobral, Ceará. 10p

McGREGOR, K.C.; MUTCHELER, C.K.; JOHNSON, J.R. \& POGUE, D.E. USDA and MAFES: cooperative soil conservation studies at Holly Springs - 1956-1996, Mississipi State, MAFES, 1996, 21p. (Bulletin, 1044). 
SEGANFREDO, M.L.; ELTZ,, F.L.F. \& BRUM, A. C. R. Perdas de solo, água e nutrientes por erosão de culturas em plantio direto. R. Bras. Ci. Solo, 21: 287-291, 1997.

SCHINCK, J; BERTOL, I.; BALBINOT JÚNIOR, A.A. \& BATISTELA. O Erosão hídrica em cambissolo húmico alumínico submetido a diferentes sistemas de preparo e cultivo do solo: II Perdas de nutrientes e carbono orgânico. R. Bras. Ci. Solo, 24: 437-426, 2000.

SILVA, I. F. de.; ANDRADE, A. P. de.; CAMPOS FILHO, O. R. Erodibilidade de seis solos do semiárido paraibano obtida com chuvas simulada e método nomográfico. R. bras. Ci. Solo, Campinas, 10: 283-287. 1986. 